\title{
Acne fulminans associated with lymecycline intake: a case report
}

This article was published in the following Dove Press journal:

Clinical, Cosmetic and Investigational Dermatology

\author{
Bruno Gualtieri \\ Annalisa Tonini \\ Salvatore Panduri \\ Andrea Chiricozzi \\ Marco Romanelli \\ Department of Dermatology, \\ University of Pisa, Pisa, Italy
}

Correspondence: Bruno Gualtieri Department of Dermatology, University of Pisa Via Roma 67, 56I26 Pisa, Italy Tel +393290060388

Email brunogualtieri86@gmail.com

\begin{abstract}
Acne fulminans (AF) is a rare acne variant characterized by sudden onset of painful nodules on the face, chest, and back in the presence of systemic symptoms. Pharmacologic agents such as steroid hormones and isotretinoin are well-known triggers, and several cases have been described. We report a case of AF occurring a few days after lymecycline therapy initiation.
\end{abstract}

Keywords: onset, systemic symptoms, steroids, trigger, isotretinoin, scars

\section{Introduction}

Acne represents a very common condition among the adolescents. While mild forms can be regarded simply as an aesthetic problem, severe forms impact deeply the patients quality of life.

Treatment is currently based on a multi-step approach depending on severity disease and tendency to develop scars. Paradoxically, the same drugs used to treat this condition can induce a dramatic worsening in patients suffering from a preexiting nodular acne. ${ }^{1}$ Drug induced-acne fulminans manifests with the abrupt onset of several ulcerated nodules accompanied by fever and polyarthralgias, few days or weeks after a pharmacological therapy initiation.

Isotretinoin, currently the drug of choice for the treatment of severe acne, represents the most common eliciting drug in this clinical setting. ${ }^{1}$

Rarely, also antibiotic agents have been reported as pharmacological triggers.

\section{Case presentation}

A 15-year-old patient was referred to our department because of a nodular acne involving chest and back, associated with atrophic scars. The patient presented with good general health conditions, with neither personal nor family history of severe acne, endocrine, or rheumatologic disorders. Furthermore, he denied intake of medications which may cause acne vulgaris or acneiform eruptions development, including steroids, lithium, phenytoin, isoniazid, and B-complex vitamins. According to disease severity, systemic antibiotic therapy (lymecycline $300 \mathrm{mg}$ daily for 8 weeks) was prescribed. After 4 days of treatment, a dramatic onset of multiple painful, ulcerated nodules on the trunk (Figure 1), associated with mild fever, headache, and diffuse arthralgias, occurred. Blood tests revealed a white blood count of $11.460 / \mathrm{mm}^{2}$ and an erythrocyte sedimentation rate of $45 \mathrm{~mm} / \mathrm{h}$, without any other 

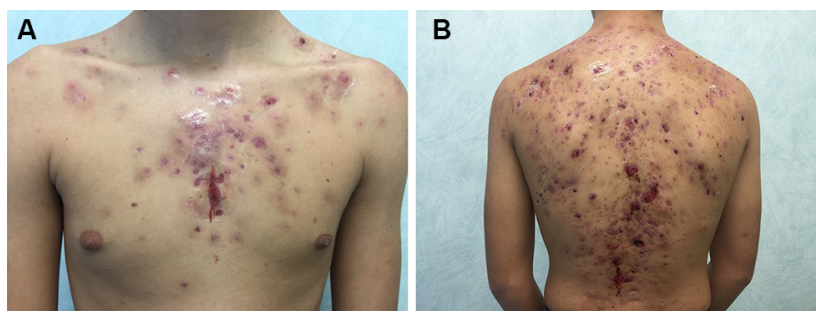

Figure I A few days after starting lymecycline for nodular acne of the trunk, a dramatic worsening of the clinical picture, with the occurrence of multiple, painful ulcerated nodules on the chest $(\mathbf{A})$ and shoulders (B) associated with malaise and arthralgias, was observed.

abnormality. Despite joint pain, rheumatologic examination showed an absence of functional impairment, and ultrasonographic imaging of the right knee and the left shoulder revealed no significant alterations. Based on clinical and laboratory findings, diagnosis of acne fulminans (AF) was made. Lymecycline was withdrawn, and corticosteroid therapy (prednisone $0.7 \mathrm{mg} / \mathrm{kg} /$ day) introduced. After 3 weeks, a global improvement was observed. In order to taper down corticosteroid dosage, isotretinoin was introduced at an escalating dose starting from $0.3 \mathrm{mg} / \mathrm{kg} /$ day up to $0.7 \mathrm{mg} / \mathrm{kg} /$ day, combined with low-dose $(0.5-0.3 \mathrm{mg} /$ $\mathrm{kg}$ /day) prednisone, which was gradually reduced over an 8 -week period. After 16 weeks, once the isotretinoin cumulative dose was $90 \mathrm{mg} / \mathrm{kg}$ and the inflammatory lesions had almost completely resolved in atrophic scars (Figure 2), retinoid therapy was withdrawn. At the 6-month follow-up visit, no signs of relapse were reported, while atrophic scars had turned into keloids (Figure 3).

\section{Consent}

The patient and his parents gave their written informed consent for the publication of images and information.

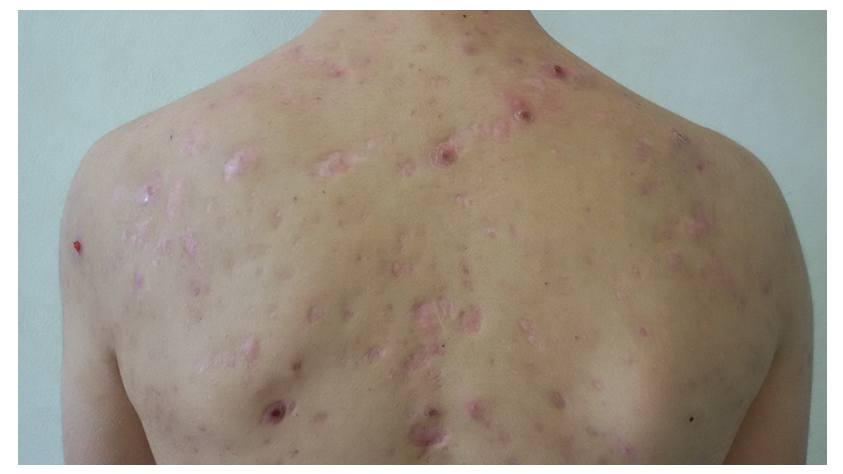

Figure 2 Regression of inflammatory nodules after 16-week isotretinoin treatment resulting in atrophic scars.

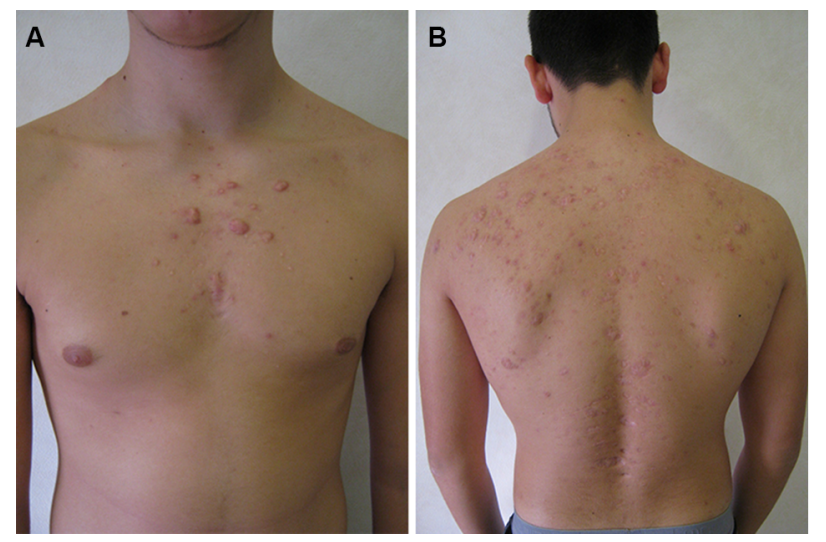

Figure 3 At follow-up visit 6 months after therapy cessation, no sign of relapse was observed. Some keloid scars developed on the chest (A) and shoulders (B).

\section{Discussion}

$\mathrm{AF}$ is a rare variant of acne characterized by sudden onset of painful nodules on the face, chest, and back in the presence of systemic symptoms, such as fever, headache, malaise, arthralgias, and myalgias. ${ }^{1}$ When these latter symptoms are not present and cutaneous signs dominate the clinical picture, some authors prefer to define this condition as "pseudo acne fulminans" or "acne fulminans sine fulminans". 1

Etiopathogenesis is not completely elucidated, though progress in the understanding of pathogenic mechanisms has demonstrated that sebocytes largely contribute to the normal function of skin barrier, and play an important role in skin innate immunity and detoxification. ${ }^{2}$ Many factors control sebaceous gland function in physiologic and pathologic conditions, such as sex steroids, growth factors, neuropeptides, antimicrobial peptides, and adipokines that may influence sebaceous gland biology by binding with several receptors located on the lipidic membrane. ${ }^{2}$

It has been proposed that genetic, immunologic, and hormonal mechanisms, especially androgens influence, may have a role in AF pathogenesis. This hypothesis is supported by the epidemiologic datum: indeed, male adolescents between 14 and 17 years represent the most susceptible population, probably because of the intense secretion of androgens that characterizes this subset. Moreover, AF has been described as a rare complication of high-dose testosterone therapy in adolescents with a hereditary tall stature ${ }^{3}$ such as in bodybuilders following abuse of anabolic hormones. ${ }^{4}$

It also represents a rare complication of isotretinoin treatment. Isotretinoin is supposed to induce fragility of the pilosebaceous duct, thus exposing a great amount of Propionibacterium acnes antigens to the immune system. This 
phenomenon may lead, in some individuals (mostly male adolescents), to an exaggerated hypersensitivity reaction of types III and IV, and dramatic worsening of acne associated with systemic involvement of variable entity. ${ }^{5}$

Although isotretinoin is the most frequent trigger in druginduced forms, antibiotics (i.e., tetracycline, erythromycin, and pristinamycin) have been occasionally mentioned as causative agents in some patients. ${ }^{6,7}$

Lymecycline belongs to the tetracycline antibiotics group and is largely prescribed to treat inflammatory forms of acne. ${ }^{8}$ Because of bactericidal and bacteriostatic action against $P$. acnes, anti-inflammatory properties, and an excellent safety profile, this drug is currently used as first choice when a systemic antibiotic therapy is required.

Nowadays, cases reporting lymecycline as a trigger of AF are not present in the literature. Considering (i) previous (though anecdotal) reports linking antibiotics to AF, (ii) close temporal relationship between treatment initiation and worsening of the clinical picture, and (iii) prompt improvement following drug discontinuation and the relatively benign course in the following weeks, the association between lymecycline intake and the onset of AF might be indicated.

In conclusion, AF represents a rare, dramatic, disabling acne variant occurring especially in young male individuals, characterized by sudden worsening of acne, with onset of nodular, ulcerative lesions associated with systemic symptoms and usually healing with scars. Because AF occurrence may be rarely related to the use of antibiotic agents, such as tetracycline, erythromycin, and pristinamycin, we sought to report the association with lymecycline use.

\section{Disclosure}

The authors report no conflicts of interest in this work.

\section{References}

1. Grando LR, Leite OG, Cestari TF. Pseudo-acne fulminans associated with oral isotretinoin. An Bras Dermatol. 2014;89(4):657-659.

2. Zouboulis CC, Picardo M, Ju Q, et al. Beyond acne: current aspects of sebaceous gland biology and function. Rev Endocr Metab Disord. 2016;17(3):319-334.

3. Weimann E, Böhles HJ. [Acute acne fulminans et conglobata after the end of high-dose testosterone therapy for hereditary tall stature]. Klin Padiatr. 1999;211(5):410-412. German [with English abstract].

4. Kraus SL, Emmert S, Schön MP, Haenssle HA. The dark side of beauty: acne fulminans induced by anabolic steroids in a male bodybuilder. Arch Dermatol. 2012;148(10):1210-1212.

5. Karvonen SL, Rasanen L, Cunliffe WJ, et al. Delayed hypersensitivity to Propionibacterium acnes in patients with severe nodular acne and acne fulminans. Dermatology. 1994;189:344-349.

6. Alakeel A, Ferneiny M, Auffret N, Bodemer C. Acne fulminans: case series and review of the literature. Pediatr Dermatol. 2016;33(6):e388-e392.

7. Karvonen SL. Acne fulminans: report of clinical findings and treatment of twenty-four patients. J Am Acad Dermatol. 1993;28(4):572-579.

8. Nast A, Dréno B, Bettoli V, et al. European evidence-based (S3) guideline for the treatment of acne - update 2016 - short version. J Eur Acad Dermatol Venereol. 2016;30:1261-1268.
Clinical, Cosmetic and Investigational Dermatology

\section{Publish your work in this journal}

Clinical, Cosmetic and Investigational Dermatology is an international, peer-reviewed, open access, online journal that focuses on the latest clinical and experimental research in all aspects of skin disease and cosmetic interventions. This journal is included on PubMed. The manuscript management system is completely online

\section{Dovepress}

and includes a very quick and fair peer-review system, which is all easy to use. Visit http://www.dovepress.com/testimonials.php to read real quotes from published authors 